\title{
The Economics of Ending Canada's Commercial Harp Seal Hunt
}

\author{
John Livernois ${ }^{1}$
}

March 5, 2009

${ }^{1}$ Professor, Department of Economics, University of Guelph, Guelph, Ontario, Canada N1G 2W1. email: live@uoguelph.ca; telephone: 1-519-824-4120 ext. 58946; fax: 1-519-7638497 


\begin{abstract}
The roots of the Canadian harp seal hunt can be traced to the $16^{\text {th }}$ Century. But in the mid- $20^{\text {th }}$ century, opposition to the commercial hunt became widespread after television images of seal pups being killed with clubs on the pack ice off the coast of Newfoundland were broadcast around the world. International conservation groups, animal welfare groups, animal rights groups, and foreign governments have been calling for the Canadian government to end the commercial seal hunt on the grounds that it is inhumane and that harvest levels are unsustainable. The Canadian government defends the traditional practices of hunting harp seals, argues that seal pelts are an important source of income for sealers, and insists that the killing methods are humane and that harvest levels are sustainable. Emotions run high on both sides of the debate. The purpose of this paper is to evaluate whether or not there is a purely economic argument for ending Canada's commercial seal hunt. The paper finds that the benefits of ending the commercial hunt exceed the costs, but not unequivocally. However, the paper argues there should be a higher criterion - the Pareto criterion - for ending the commercial hunt; that is the hunt should end only if winners compensate the losers. The paper goes on to argue that an effective way to satisfy this criterion is to introduce a system of individual transferable quotas (ITQs) and let the market reveal the value of the commercial seal hunt. In addition to many other advantages such as improving the safety and efficiency of the hunt, the ITQ market could provide a mechanism by which those willing to pay to end the hunt could do so directly to sealers thereby ensuring that the hunt is scaled back or ultimately ended only when it is economically efficient and unambiguously welfare-improving.
\end{abstract}

Keywords: seal hunt, common property; economic efficiency; individual transferable quotas. 


\section{Introduction}

The commercial harp seal hunt in eastern Canada is rich in both history and controversy. Its roots can be traced to the $16^{\text {th }}$ Century when fishing vessels sailed from Europe to harvest seals during the birthing and mating rituals on the late-winter pack ice off the coast of Newfoundland and in the Gulf of St. Lawrence. But in the mid-20 $0^{\text {th }}$ century, opposition to the commercial hunt became widespread after television images of seal pups being clubbed to death were broadcast around the world. For decades now, international conservation groups, animal welfare groups, animal rights groups, and foreign governments alike have been calling for the Canadian government to end the commercial seal hunt on the grounds that the killing methods are inhumane and that harvest levels are unsustainable. ${ }^{2}$ The Canadian government, on the other hand, defends the traditional practices of hunting harp seals, argues that seal pelts are an important source of income for sealers, and insists that the killing methods are humane and that harvest levels are sustainable [1].

For most involved in the debate over whether or not the commercial seal hunt should be ended, the issue is highly emotional. Parties on both sides of the debate expend not only considerable energy but considerable resources to further their cause. Opponents to the hunt make significant donations to non-governmental organizations that conduct information campaigns world-wide and often send scientists and specialists to monitor the hunt. Defenders of the hunt also expend considerable resources conducting information campaigns, funding lobbyists to promote the seal hunt and to establish new markets for pelts and other products. The federal government in addition expends considerable resources managing the resource, establishing and enforcing regulations for the hunt and monitoring the hunters and the individual observers who are also subject to regulations. For anyone familiar with the theory of common property resources which argues that little in the way of economic surplus is likely to be generated by the exploitation of harp seals, it may seem surprising that the Canadian government could spend so much fighting for so little.

The purpose of this paper is to evaluate whether or not there is a purely economic argument for ending Canada's commercial seal hunt. The aggregate benefits and costs of ending the hunt are estimated to determine whether or not there would be an economic efficiency gain from ending the hunt. However, the paper goes on to argue that while the existence of an efficiency gain is a necessary condition for ending the hunt, it is not sufficient. Instead, all parties involved must be made better off by the ending of the hunt for this to be the politically and economically desirable outcome. In other words, the outcome must be Pareto improving. The paper goes on to discuss alternative mechanisms - buy outs, reverse auctions, and individual transferable quotas - that could produce a Pareto-improving outcome.

In the next section, background on Canada's commercial harp seal hunt is provided. The

${ }^{2}$ For example, the United States, Belgium and the Netherlands have banned trade in seal products; the European Union banned the trade in whitecoat harp seals and blueback hooded seals in 1983 and is currently considering a bill that would ban imports of all seal products; the Humane Society of the United States has organized a boycott of all Canadian seafood products to protest the seal hunt. 
third section examines the economics of the commercial seal hunt beginning with a brief discussion of the classic common property problem in the context of the seal hunt. It is argued that this has led to low earnings for and extreme risk-taking by sealers. Next, the earnings of sealers, the economic costs of risk, and the cost of government support are estimated and the section is concluded by weighing up the benefits and costs of ending the hunt. In Section 4, the empirical evidence on buyouts of fisheries is reviewed and an ITQ mechanism is proposed in which the market would determine whether the seal hunt should be ended or not. Finally, conclusions are drawn in section 5.

\section{Background on Canada's Commercial Harp Seal Hunt ${ }^{3}$}

One of three distinct populations of harp seals (the other two are found in the White Sea and off the east coast of Greenland) the Canadian population summers in the Arctic and begins its annual southward migration towards Newfoundland in the fall. Beginning in late February, pregnant females give birth (whelp) on the pack ice in the Gulf of St. Lawrence (the "Gulf” herd) or off the coast of northern Newfoundland (the "Front" herd). Pups, born with white fur (and referred to as "whitecoats"), are weaned after about 12 days but remain on the pack ice as they mature and shed their white fur. The moult is completed about 25 days after birth and the pups now referred to as "beaters" - have a mottled-looking darker coat. Although they are capable of swimming, most beaters remain on the pack ice for a few more weeks until it breaks up. They follow the ice as it recedes northward, usually in early May.

Traditionally, seal pups - primarily whitecoats - were killed on the pack ice in March and April each year when they were relatively accessible and immobile. By the middle of the $19^{\text {th }}$ Century, the commercial seal hunt was second in importance to the cod fishery for the Newfoundland economy. However, over-exploitation in these years led to a severe decline in the harp seal population and a consequent reduction in the harvest. The industry did not recover until after WWII (during which harvesting was stopped and the population recovered), only to decline again due to over-exploitation of the stock from the 1950s to 1970s.

The first television accounts of the hunt were broadcast in 1964. Images of whitecoats being killed, usually by a blow to the head, were shown to viewers around the world. The scenes of baby seals, beaten and bloodied on the white pack ice, led to the birth of the international antisealing movement and the birth of the conflict and controversy surrounding the harp seal hunt.

In response to scientific concerns and public protests against the alleged inhumanity of the seal hunt, the Canadian government introduced regulations for the first time in 1965 requiring licensing of hunters and controls on killing methods in an effort to ensure the hunt was humane, and in 1971 introduced a total allowable catch (TAC) in an effort to protect the population from over-exploitation. However, the anti-sealing movement strengthened as images of bloodied white coats continued to be broadcast around the world.

Figure 1 shows the historical catch and TAC for harp seals from 1971 to 2008. In 1983, the European Commission implemented a ban on products derived from whitecoats. The impact

\footnotetext{
${ }^{3}$ This section is based primarily on Lavigne and Kovacs [2].
} 
of the resulting drop in demand is apparent in Figure 1: the annual catch fell from over 150,000 pelts to below 50,000 and the TAC was never a binding constraint. In 1987, the Canadian government banned the commercial hunt for whitecoats, presumably in response to pressure from anti-sealing groups and the European ban. In 1996, however, the industry was revitalized, in part due to subsidies introduced by the Canadian government on the harvesting of beaters (a few days older than whitecoats) and due to a sudden growth in demand for beater seal pelts. Once again the industry began harvesting large quantities of pups, limited only by the TAC.

FIGURE 1 HERE

\section{The Economics of the Commercial Harp Seal Hunt}

Harp seals are harvested mainly for their pelts. Most pelts are cured in Newfoundland and then exported to Norway (about 60\% in 2006), Finland (18\%), Germany (13\%), China (6\%), and a number of other countries for processing [3]. According to the International Council for Exploration of the Sea [4], the Canadian harvest of harp seals accounted for more than two-thirds of the world harvest of harp seals in recent years. The total Canadian commercial harvest is subject to a TAC which is set by the Department of Fisheries and Oceans (DFO) to safeguard the maintenance of the stock of harp seals though it is also influenced by market conditions. "Where there is an abundant resource, ...[the criteria for setting the TAC] ... will facilitate a market-driven hunt that will enable sealers to maximize their benefits without compromising conservation.”[5]

\subsection{Common Property and the Race to Hunt}

The distinguishing feature of the commercial harp seal harvest is the open-access, common-property nature of the resource. ${ }^{4}$ Property rights to seal pelts are established by being the first to harvest them. It is well known that this leads to the so-called "tragedy of the commons" in which harvesting effort is excessive, the population can be driven to low levels, and economic surplus (rent) for harvesters is driven to zero. Indeed, these characteristics paint an accurate picture of the commercial seal hunt off the eastern coast of Canada in the mid 19th Century when the seal harvest reached a peak of 740,000 and then fell off dramatically because the stock collapsed and again in the early 1970s when the stock of seals reached an historic low [2]. Reacting to this decline, the Canadian government introduced a TAC for the first time in 1971.

A TAC, if properly enforced, limits the total harvest and therefore solves one of the problems associated with an open-access, common-property resource: excessive harvest levels. However, because it does not limit harvesting effort, it is well known that it does not solve the

${ }^{4}$ Although the hunt is open only to licensed hunters, it is effectively an open-access resource because the number of licenses issued is nearly twice as large as the number of licensees who actually participate in the hunt. 
economic problems associated with the tragedy of the commons, namely that economic surplus is driven to zero by excessive competition for the allowable harvest. Because the hunt is stopped when it becomes apparent the TAC will be reached, participants have an incentive to hunt as rapidly as possible to maximize their share of the TAC. ${ }^{5}$ As long as the net return from increasing one's costly harvesting effort is positive, it pays to do so. As harvesters respond to this economic incentive, aggregate harvesting effort and the cost of the hunt rise until an equilibrium is reached where the net return from further increases in effort is zero.

In many fisheries around the world that have been subject to a TAC, entry is limited by the number of fishing licenses issued. As a result, the only way that harvesting effort can be increased is to increase the harvesting capacity of each license. Larger, faster and ultimately far more costly boats with more sophisticated equipment and gear are introduced in the race to catch the most fish, the fastest. The cost of the harvest and the speed with which the TAC is reached rise dramatically. For example, in the British Columbia halibut fishery, the length of the season fell from 65 days in 1980 to 6 days in 1990 due to the introduction of a TAC [6].

In Canada's commercial seal hunt, the number of sealing vessels that can participate in the hunt is effectively unlimited. As a result, excessive capitalization has taken the form of an increase in the number of participating vessels rather than as an increase in the capacity of individual vessels. ${ }^{6}$ For example, in 1996 the profitability of the sealing industry was revived due to the introduction of government subsidies and a rise in demand. In that year, 600 hunters [7] and 300 vessels [8] participated in the hunt, and the average vessel took 810 pelts. However, the increased profitability was rapidly eroded in subsequent years as the number of participating vessels and hunters swelled. In the 2005 hunt, 7,000 hunters and 1,800 vessels participated in the hunt [5], and the average vessel took just 183 pelts. Not surprisingly, the quota for harp seals is often reached in just two or three days in most regions.

There remain two other serious manifestations of the incentive to hunt rapidly. First, the race to hunt creates an incentive for hunters to violate the regulations that govern the manner in which the seals must be killed, bled and skinned. The regulations are in place to increase the likelihood that killing methods are humane but they inevitably slow down the hunt. The temptation to bend the rules is palpable and there is evidence to suggest that non-compliance sometimes occurs $[9,10]$.

Second, because the seal hunt has become a race in which the fastest hunters reap the greatest rewards, sealers are driven to take greater risks than they otherwise would. Often, they have little choice but to attempt to reach the seal herd even in unsafe ice-infested waters. To do otherwise would be to concede the pelts to a vessel that is willing to take the risk. Excessive risk taking raises not only the private cost of the hunt in the sense that greater risk taking leads

${ }^{5}$ The TAC for harp seals has been exceeded in some years but usually by less than $5 \%$.

${ }^{6}$ Participants must be licensed seal hunters. However, the number of licenses issued each year is at least twice as high as the number who wish to participate in the hunt. As a result, the number of vessels that can participate is effectively unlimited (or at least it is limited only by the number of vessels that exists). However, the government does restrict the size of vessels to be less than 65 feet. 
inevitably to more damage to vessels and loss of life, but it raises the public cost of the hunt because of the increased demand on the search and rescue resources of the Coast Guard. Next the evidence on the risks in sealing is examined.

\subsection{A Culture of Risk-Taking}

Sealing is an inherently risky activity because it is conducted in pack ice which can shift unpredictably due to ocean currents and changing winds. It is common for sealing vessels to become trapped in ice and, indeed, to become damaged and crushed by ice. To make matters worse, most sealing vessels are not designed for operating in ice-infested water. Instead, they are typically wooden or fibre-glass reinforced fishing boats designed for operation in open water. Their hulls, rudders, shafts and propellers are seldom strengthened to withstand the pressure and weight of ice [11].

A number of examples illustrate the risks. ${ }^{7}$ In the 2008 hunt, the sealing vessel Acadien II suffered ice damage to its rudder and, as a result, lost directional control. Tragically, while under tow by a Canadian Coast Guard icebreaker, the vessel capsized and four men perished. In the 2007 hunt, more than 100 sealing vessels became trapped in the ice for weeks. In the 2005 hunt, the wood-hulled fishing Vessel Justin $M$, became trapped in ice and sank after sustaining significant damage to the hull. All nine crew members were rescued. In its report on the sinking, the Transportation Safety Board indicated that several other vessels were also trapped in ice at this time, with each suffering some damage to the extent that the Canadian Coast Guard icebreaker assistance was required to free them. In the 1997 hunt, the sealing vessel Gilbert D suffered a crushed hull and sank. Fortunately, its crew was rescued. ${ }^{8}$

In the 16-year period 1990 to 2005, 227 occurrences $^{9}$ involving fishing vessels operating in ice-infested water during the seal-hunt months of March, April and May were officially recorded by the Canadian Coast Guard. The majority of these reported occurrences involved hull damage, with a total of 21 vessels lost. ${ }^{10}$ This translates into nearly 13 occurrences per year

${ }^{7}$ These examples are taken from Transportation Safety Board Reports [12, 11, 13].

${ }^{8}$ Despite the high risk of damage or loss to vessels and notwithstanding the tragedy that befell the Acadien II, the risk of loss of life is generally relatively low in sealing due to the fact that if a vessel becomes stuck in ice, the crew can disembark and walk across the ice to a rescue vessel.

${ }^{9} \mathrm{An}$ occurrence is a reportable event such as a personal injury or death, sinking, foundering or capsizing of a vessel, or damage to a vessel that affects its seaworthiness. It also includes events such as dangerous goods being released or a shifting or loss of cargo but this type of occurrence is not likely to be relevant for sealing vessels.

${ }^{10}$ Transportation Safety Board [11]. The report also indicates that many occurrences go unreported. 
(excluding lost-vessel-occurrences) and about 1.3 vessels lost per year. After correcting for changes in the level of activity over these years ${ }^{11}$, the estimated frequency is about 13 occurrences per 1000 vessels operating per season and about 1.3 vessels lost per 1000 vessels operating per season. In the next section, these frequencies, along with assumptions about the cost of lost and damaged vessels, are used to estimate the cost of risk in the sealing industry.

Risk-taking is further encouraged by the resource management policy governing the commercial seal hunt. Specifically, the policy of regulating the harvest by way of a TAC induces sealers to take great risks to garner as large a share of TAC as possible before the hunt is closed. The report on the sinking of the Justin $M$ by the Transportation Safety Board [11], provides a striking example of the kind of risk-taking behaviour that is typical in the sealing industry. According to the report, the Justin M left port and arrived at the ice pack south of the Magdalen Islands a full three days before the hunt was set to open. A herd of approximately 300 seals was spotted and the captain chose to keep the vessel near the herd while waiting for the opening of the hunt. Despite repeated warnings of the developing ice pressure due to strong winds, the Justin $M$ remained in the pack ice in anticipation of the opening of the seal hunt as did a number of other sealing vessels. Exposing the vessel and crew to three full days of pack ice before hunting can even begin is clearly an example of the unnecessary risk-taking that captains are induced to take to be the first and fastest under the TAC policy. In this instance, the risk-taking did not pay off for the Justin M. Just hours before the opening of the hunt, the pressure of the ice began to crush its hull. A distress call went out. Two Canadian Coast Guard icebreakers were within 1.5 hours of the vessel and were able to rescue the crew but not save the vessel. The Justin $M$ sank just a few hours after making the initial distress call. Several other vessels were trapped in ice at around the same time and each suffered damage to varying degrees. At least two of them required icebreaker assistance.

The report on the sinking concludes that the global quota system (TAC) put in place by DFO to manage the fishery “ ... fosters a culture of risk in the sealing industry rather than a culture of safety. ... [It results in] an environment of intense competition whereby the first and the

${ }^{11}$ Ideally, one would use data on the number of vessels participating in the hunt each year over this period to calculate accident frequencies. However, the only data for the number of vessels participating in the hunt are for the years 2005 and 1996. The catch per vessel in 2005 was 183 and in 1996 it was 810. To estimate the number of vessels in years for which there are no data on number of vessels, divide the reported catch each year by the catch per vessel in either 1996 or 2005 . Using the 2005 catch per vessel will lead to an overestimate of the number of vessels participating, at least in the early years, and therefore underestimate the risk. Using the 1996 catch per vessel will produce the opposite outcome. The 2005 value is chosen because it is consistent with the strategy adopted in the paper of erring on the side of under-estimating costs and over-estimating earnings. Thus, after dividing the actual catch each year, for which there are data, by the assumed catch per boat, one obtains an estimate of the number of boats participating in the hunt each year. The resulting estimated frequencies of "occurrences" and lost vessels are 0.0126 and 0.00129 respectively. 
fastest reap the greatest rewards." ${ }^{2}$

Further evidence of the risk-taking behaviour of sealers is the very high levels of insurance deductibles set for sealing vessels. For a vessel valued at $\$ 500,000$ or more, there is a $\$ 150,000$ deductible while fishing in ice and a $\$ 250,000$ deductible while engaged in the seal fishery. A normal deductible while not fishing in ice is $\$ 5,000$ [14].

\subsection{Earnings of Seal Hunters}

Theory predicts that the economic surplus from harvesting is driven to zero in a commonproperty resource such as the harp seal industry. In practice, this implies that the earnings of sealers just cover the opportunity costs of participating in the hunt. Problematic is the fact the most of the opportunity costs are intangible and unobservable. For example, for many sealers, the alternative to sealing is leisure time and/or home production until the crab fishery opens in late spring. Therefore, there is probably little in the way of foregone earnings. Instead, the main opportunity cost to seal hunting is the disutility of working hard in a harsh and dangerous environment rather than enjoying leisure time or doing non-market home production such as repairs and maintenance to houses and vessels. There is no doubt that there must be an expectation of reasonable earnings to induce men to endure the difficult and dangerous conditions present in the seal hunt. Indeed, this is the strongest evidence that the disutility costs are real, even if intangible. It is also the only evidence, however, and this makes the task of calculating a fair level of compensation, should the hunt be closed, extremely difficult. In this section, a more detailed examination of sealers' earnings is conducted in an attempt to establish an upper limit on compensation.

Southey [7] estimates earnings to be about $\$ 6700$ per sealer in 1996 when seal meat was directly subsidized and seal penises were part of the revenue source ${ }^{13}$. However, the estimates obtained in this paper using more recent data suggest that earnings per sealer are now much lower. There are now no subsidies and sales of penises, meat and other by-products (other than the pelt) fetch negligible revenues. More importantly, the number of participants and vessels in the industry has soared. Southey [7] reports there were about 600 active sealers in 1996 and the Seal Industry Advisory Council [8] estimates there were 300 vessels in the hunt. According to

${ }^{12}$ The Transportation Safety Board [11] notes that DFO responded by modifying its system for allocating the global TAC. In particular, the Gulf share of the global quota was to be allocated among four separate sub- regions and the start dates for different regions were to be varied. The intention of these changes was to lower the number of sealers in any one region at any one time. However, it is doubtful that these changes will do much to alleviate the incentive to take risks because the competition to be first and fastest will still exist within each sub-region; moreover, there may be competition between regions in the sense that a quota over-run in one region may lead DFO to reduce the quota in another region.

${ }^{13}$ All values in this section are adjusted for inflation to 2008 dollars using the Consumer Price Index. 
the DFO [5], 7000 hunters and 1800 vessels participated in the hunt in 2005. Since the total harvest of pelts was only about one-third higher in 2005, it is not surprising that earnings per sealer have declined substantially.

Estimating sealers' earnings is fraught with difficulties because of the limited information available. Moreover, earnings vary from year to year and from one individual to another. The best one can hope for given the data that are available is to estimate earnings for a representative sealer averaged over the past few years.

The approach taken here to estimating the average earnings per sealer can be outlined as follows. Total Landed Value for the industry, all regions, in a given year, $V_{T}$, is given by

$$
V_{T}=V_{L} N_{L}+V_{S} N_{S}
$$

where $V_{L}$ and $V_{N}$ are landed values for "large" and "small" vessels respectively. Small vessels are defined by DFO as being less than 10.67 metres (35 feet) and large vessels are defined to be between 10.67 metres and 19.81 metres (65 feet). ${ }^{14} N_{L}$ and $N_{S}$ are the number of large and small vessels respectively participating in the hunt.

Similarly, the total cost of operating all vessels combined is given by

$$
C_{T}=C_{L} N_{L}+C_{S} N_{S}
$$

where $C_{i}, i=L, S$, is the total operating cost per vessel for large and small vessels during the sealing season.

Net landed income for the industry then that is available to be shared among sealers is

$$
Y_{T}=V_{T}-C_{T}
$$

If $n$ is the number of participating sealers, then average earnings per sealer is given by

$$
y=\frac{Y_{T}}{n}
$$

Data for $V_{T}$ are readily available for recent years and are presented in constant 2008 dollars in Figure 2 along with the number of pelts landed. The first notable feature of these six years of data is the spike in landed values in 2006. Virtually all of the spike is accounted for by the spike in prices for seal pelts as is apparent by the fairly unchanging number of landed pelts. Figure 2 also shows that the TAC was exceeded in each of 2004, 2005 and 2006. Landed value fell dramatically in 2007 and 2008 both because the number of landings fell short of TAC (largely due to poor ice conditions) and because prices for seal pelts dropped significantly.

\section{FIGURE 2 HERE}

Data for $C_{T}$ are more difficult to come by. The only reliable cost data available are based on a survey conducted in 1996 which provides estimates of the average operating costs of large and small vessels [8]. However, the harvest per vessel in 1996 was 810 pelts; in 2005 only 183 pelts per vessel were harvested. Thus, individual vessels in 1996 were far more active and likely spent longer at sea than those in 2005 so it would be incorrect to apply the 1996 estimates of cost per vessel to the 2005 data without first adjusting the estimates to account for the change to the harvest per vessel. A brief overview of the methodology for adjusting the estimates of cost per

\footnotetext{
${ }^{14}$ Vessels larger than 19.81 metres are not permitted to participate in the seal hunt.
} 
vessel is provided here and the details are relegated to the appendix.

The cost survey breaks operating costs down into six categories: fuel, freight, food, ammunition, insurance and other. Since food is an expense that would be incurred regardless, it is not considered here a cost attributable to seal hunting. Assume a linear relationship between cost, in the ith category, per vessel, $c_{i}$, and the number of seals harvested per vessel, $x$ :

$$
c_{i}^{96}=a_{i}+b_{i} x^{96}
$$

where a "96" superscript refers to the 1996 value of the respective variable. Let $\alpha_{i}$ represent the proportion of the cost that is independent of the number of seals harvested. Then,

$$
\alpha_{i}=\frac{a_{i}}{c_{i}^{96}} \quad ; \quad\left(1-\alpha_{i}\right)=\frac{b_{i} x^{96}}{c_{i}^{96}}
$$

If one assumes reasonable values for the $\alpha_{i}$, then one can produce estimates of the parameters of the linear cost relationship $\left(a_{i}, b_{i}\right)$ that can be used to estimate the cost in later years. For example, for ammunition a reasonable value for $\alpha_{\mathrm{i}}$ is 0 because these costs clearly depend only on the number of seals harvested; on the other hand, a reasonable value of $\alpha_{i}$ for insurance is 1 because these costs will be the same regardless of the number of seals harvested. For the other cost categories, a value of 0.5 is assumed.

The implied adjustment to the 1996 values for cost per vessel (within in each cost category) is the following:

$$
c_{i}^{05}=c_{i}^{96}\left[\alpha_{i}+\left(1-\alpha_{i}\right) \frac{x^{05}}{x^{96}}\right]
$$

where a " 05 " subscript refers to the 2005 value of the respective variable. This says that the 2005 cost per vessel in the ith cost category equals the 1996 value multiplied by the adjustment term in square brackets. Since the 2005 harvest per vessel is only $22.6 \%$ of that for 1996 , the adjustment factor equals 0.226 when $\alpha_{i}=0,0.61$ when $\alpha_{i}=0.5$, and 1.0 when $\alpha_{i}=1$.

The estimates for the earnings of sealers are restricted to the years 2005 and 2008 due to lack of data for other years for the number of sealers and the number of large and small vessels. The 2005 landed value is $\$ 20,980,371$, about $\$ 1.9$ million above the average over the six years of data presented in Figure 2. The landed value for 2008, $\$ 7,245,691$, is considerably below the average.

The breakdown and details of the operating cost estimates are contained in the Appendix. It turns out that the estimated operating costs for vessels in 2005 (but in 2008 dollars) are \$1,678 and \$10,059 per vessel for small and large vessels respectively (excluding food costs). Using data for the number of small and large vessels in 2005, this gives an estimate of total industry operating costs, $C_{T}$, of $\$ 5,584,215$. According to the Transportation Safety Board report [12] , the number of vessels operating in 2008 was the same as in 2005. Assuming the same distribution of small and large boats as in 2005, and using the lower harvest per vessel of 121 pelts, the operating cost model generates total costs of \$5,281,898 in 2008 dollars.

Total estimated earnings to sealers is the difference between $V_{T}$ and $C_{T}$. For 2005, this is estimated to be $\$ 15,396,156$. Using $n=7000$ for the number of sealers, the estimated earnings 
per seal hunter in 2005 is $\$ 2,199$. For 2008 , this is estimated to be $\$ 1,963,793$ and earnings per sealer is estimated to be $\$ 281 .^{15}$

So far, the reported insurance costs from the 1996 survey have been used but one might reasonably suspect these to be underestimates. For example, the insurance cost per small vessel is reported to be $\$ 166$ which appears unrealistically low. The likely explanation is that some, perhaps many, small vessels surveyed did not carry insurance. In fact, Wiseman [16] reports that, in some instances, risk factors associated with sealing quite often preclude any [insurance] coverage at all. The reported insurance cost for large vessels is more credible, at $\$ 2564.95$, but is probably still an under-estimate given the data on the frequency of hull damage and lost vessels reported earlier. In an effort to produce estimates of insurance costs that are more consistent with the empirical evidence on risk, the theoretical insurance premiums are next estimated and compared to the reported insurance costs from the survey.

The Cost of Risk: The economic cost of risk in the seal industry is the additional insurance premium that a risk averse individual would be willing to pay to fully insure against possible losses from participating in the seal hunt. ${ }^{16}$ There are two types of losses: the loss of the vessel (from sinking) and the loss associated with an "occurrence", which is assumed here to mean damage to the hull. The willingness to pay for insurance is defined as the expected loss (probability of the loss multiplied by the loss) plus the risk premium (the amount a risk-averse individual would be willing to pay to avoid risk). The expected loss is a straightforward calculation once the probability of a loss and the value of the loss are known. The probabilities of the two types of losses will be assumed to equal the historical frequencies presented in the previous section. The values of the two types of losses will come from assumptions discussed below.

To estimate the risk premium, a constant relative risk aversion utility function is assumed with a value of one for the coefficient of risk aversion. This is a low level of risk aversion compared to levels estimated in the literature [17] and therefore will produce a conservative estimate of the risk premium. As above, the probabilities of losses will be set equal to the historical frequencies and the values of the losses will follow the assumptions described next.

Fishing vessels used for sealing vary in size, age and characteristics and therefore vary in value. A vessel's replacement value is assumed to range from $\$ 100,000$ to $\$ 300,000$ for small (< $10.67 \mathrm{~m})$ vessels and from $\$ 500,000$ to $\$ 1,000,000$ for large $(<19.95 \mathrm{~m})$ vessels. Similarly, the type of damage associated with an officially recorded occurrence can vary greatly. For small

\footnotetext{
${ }^{15}$ This assumes there were 7000 sealers. If, as the Canada Gazette [15] reports, only 6000 sealers participated in 2008, then earnings per sealer are estimated to be $\$ 327$.

${ }^{16}$ This is a stylized analysis in which moral hazard is assumed to be absent so there is no need for a deductible portion with the insurance coverage. In practice, moral hazard is a significant issue which is why insurance deductibles are so high. Wiseman [16] reports deductibles as high as $\$ 100,000$. The Government of Newfoundland and Labrador [14] reports deductibles as high as $\$ 250,000$. For our purposes, deductibles can be ignored since they would not significantly affect our estimated cost of risk.
} 
vessels a range of $\$ 10,000$ to $\$ 50,000$ is assumed for repairs and for large vessels the assumed range is $\$ 10,000$ to $\$ 75,000$.

Given the assumptions outlined above, the additional annual insurance premium associated with seal hunting implied by the theoretical analysis outlined in the Appendix is in the range of $\$ 552$ to $\$ 1268$ for small vessels and $\$ 1900$ to $\$ 4400$ for large vessels. ${ }^{17}$

Whether or not a vessel owner actually pays for insurance has no bearing on the fact that there is a cost associated with the risk of sealing. If the owner pays for insurance, the cost is paid in the form of insurance premiums and the risk of losses and damage is borne by the insurer. If the owner does not carry insurance, there are no out-of-pocket costs associated with risk until a vessel is lost or damage is sustained and then the costs may be staggering. However, the way to treat these costs is to impute the cost of risk bearing on annual basis regardless of whether a loss or damage occurs. The imputed cost of risk bearing is just the willingness to pay for insurance.

As expected, even the lower bound of the range of values for the theoretical insurance premium for small vessels is considerably higher than the reported average insurance paid of $\$ 166$. On the other hand, the reported average insurance paid for large vessels lies within the estimated range of values for the theoretical premium for large vessels.

If the higher insurance costs are factored in, average earnings for 2005 fall to a range between \$1929 and \$2139 and for 2008 fall to a range between \$11 and \$221 depending on whether estimated insurance costs are at the high end or low end of the range.

\subsection{Government Support}

Direct subsidies to the sealing industry were discontinued in 2000. However, the industry receives considerable federal government assistance, primarily from the Coast Guard, in the form of dedicated icebreakers, support vessels and aircraft. In a typical year, three to four icebreakers, other support vessels and aircraft assist sealing vessels for the duration of the hunt. It is difficult to obtain reliable and comprehensive estimates of the cost of this support. In 2007, the Canadian Coast Guard rescue mission is reported to have cost \$3.4 million [18]. However, that was an unusually bad ice year resulting in unusually high support costs. On the other hand, this cost estimate appears to be primarily the cost of fuel and wages and does not include an appropriate capital charge for the icebreakers and helicopters, costs that are arguably considerably higher than fuel and wage costs. One report claims that the annual Coast Guard budget is as low as $\$ 528,000$ [18] to support the seal hunt; another puts the annual cost as high as $\$ 5$ million[19]. However, it is not clear what any of these estimates include or exclude or how

${ }^{17}$ For small vessels, the low end of the range is based on a vessel valued at $\$ 100,000$, repair costs of $\$ 10,000$ and the insuree's total assets valued at $\$ 310,000$. The high end of the range is based on a vessel value of $\$ 300,000$, repair costs of $\$ 50,000$ and the insuree's total assets valued at $\$ 110,000$. For large vessels, the low end is based on a $\$ 500,000$ vessel, $\$ 10,000$ repairs and assets of $\$ 1.1$ million. The high end is based on a $\$ 1$ million vessel, $\$ 75,000$ repairs and assets of $\$ 1.1$ million. 
they were determined.

The most reliable cost estimates come from the Auditor General of Canada's analysis [20] of the Coast Guard's operations. The report says that a heavy icebreaker has a crew of 60 or more, annual operating and maintenance costs of \$5.5 million on average, and a replacement cost of about $\$ 110$ million. In a specific case study, it estimates that the cost of dedicating a single icebreaker to be on standby to support a ferry service in the St. Lawrence River for a nearly three-month period in 1988 was \$2.7 million. The icebreaker support provided for the commercial seal hunt has a shorter duration, but three or more icebreakers are involved, as are aircraft and other support vessels. If one uses the Auditor General's calculations adjusted for inflation, and assume three icebreakers are dedicated to the seal hunt, but only for one month per year, and ignore the costs of aircraft and support vessels, one obtains a figure of about $\$ 4.3$ million per year as an estimate of the full cost (operating, maintenance and an annualized charge for capital) of providing icebreaker support for the commercial seal hunt.

In addition to icebreaker support during the hunt, both the federal and Newfoundland governments spend annually on pro-sealing marketing campaigns around the world on behalf of the industry to help develop markets for seal pelts and seal products. For example, the Government of Newfoundland is reported to budget \$100,000 per year to support pro-sealing rallies, purchase pro-sealing advertising, and to cover travel expenses for market-development [21]. The Government of Canada's “Ambassador for Fisheries Conservation” reports personal annual travel expenses on seals-related business over \$70,000 in 2008 [22]. The full cost probably reaches three or four times this amount when the travel expenses of staff are included; however, a conservative assumption of a total of $\$ 100,000$ annually is used for all travel expenses on seals-related business. Together with Newfoundland's expenditures, this is a total of $\$ 200,000$ annually, at a minimum, in support of the seal hunt. And recently, the federal government filed a claim for $\$ 487,000$ against the protest vessel the Farley Mowat to recover costs incurred for holding the vessel since it was seized in April 2008 for allegedly violating the regulations that require non-sealers to have an observer permit to be within one kilometre of the seal hunt [23]. Although this particular incident is a one-time cost to the federal government and hence will not be included in the following calculations, it is indicative of the unplanned costs that can arise because of the strength of conviction of the protest movement.

The federal government incurs additional costs to regulate the commercial hunt, monitor the hunt, monitor observers and protesters and enforce the regulations regarding hunters and observers. No data are available to provide an estimate of the cost of these activities though one could reasonably assume the annual cost would be measured in millions of dollars. However, in the absence of a reliable estimate of the cost, it is not included in the following quantitative evaluation of the costs and benefits of ending the seal hunt. Nevertheless, one can safely assume that substantial federal government expenditures would be eliminated in the long run were the commercial hunt to be ended.

\subsection{The Aggregate Costs and Benefits of Ending the Hunt}

The cost of ending the seal hunt is the loss of the economic surplus (economic rent) 
earned by seal hunters and processors of seal pelts. ${ }^{18}$ As was argued earlier, the theory of common property resources suggests that the economic surplus is driven to zero in equilibrium; that is, earnings are just high enough to compensate sealers for the risks, disutility, and other opportunity costs of participating in the hunt. However, because of the limited alternative employment opportunities in the region, the major part of the opportunity costs are intangible and difficult to quantify. The most common assumption made in the economics literature is that the opportunity cost of leisure time is a fraction, usually one-third, of the wage rate although recent research suggests that the true fraction may be somewhat lower [24, 25]. Therefore, the assumption made here is that the opportunity cost of sealers' time is between zero and one-third of the minimum wage in Newfoundland, which is $\$ 8$ per hour. Sealers are assumed to work an average of 125 hours in the hunt. Therefore, the assumed opportunity cost is in the range zero to $\$ 333$ per hunter per year.

Total earnings to sealers were estimated to be about $\$ 15.4$ million, net of operating expenses, for the 2005 commercial seal hunt and about \$2.0 million for the 2008 hunt. Such a large variation in earnings over just a three-year period combined with a paucity of earnings data for other years makes it difficult to be precise about estimating the expected costs of ending the seal hunt. It helps to look at market conditions in those years.

To put the 2005 and 2008 markets into historical context, turn to Figure 3 which shows average pelt prices from 1971 to 2008 in constant 2008 dollars. ${ }^{19}$ It is immediately apparent that 2006 was an outlier year: the average pelt price was $\$ 109$, more than $50 \%$ higher than in any other year. At \$63, the 2005 price was the next highest in the period since 1998. Over the period since 1998, prices averaged about $\$ 49$ and reached a low of about $\$ 33$ in 2008. Thus, a reasonable conclusion to draw from the historical data on pelt prices is that the market in 2005 was exceptionally strong. Therefore, sealers total earnings in 2005 were likely exceptionally high as well. On the other hand, the market in 2008 appears to have been exceptionally weak.

The price data suggest that sealers’ earnings are not likely to be as high as \$15.4 million or as low as $\$ 2$ million on average in the future. If prices for seal pelts in the future average about \$49, the same as the historical average using the data in Figure 3 and also roughly the midpoint between the 2008 and 2005 pelt prices, then one might reasonably expect earnings to average about $\$ 8.7$ million annually in the future. After subtracting the assumed opportunity cost of sealing, the cost of ending the commercial hunt is estimated to lie between $\$ 6.5$ million and $\$ 8.7$ million per year.

${ }^{18}$ Ending the commercial seal hunt would also lead to a loss of work for processing plants in Newfoundland. By not counting this as a cost of ending the hunt, it is assumed that the earnings of all factors of production in processing, from capital to labour, are just enough to cover their opportunity costs. Hence, there is no loss of economic surplus in the long run associated with a reduction in the activity levels of processing plants.

${ }^{19}$ Prices in the 1980s and earlier are for whitecoat seal pups. For later years, the prices are for beater seal pups so the prices are not perfectly comparable. Whitecoat and beater pelts are assumed to be close enough substitutes that the price comparison is meaningful, but the focus is primarily on prices since 1998 . 
The benefits of ending the commercial seal hunt are the saving of resources currently allocated by governments to support and manage the seal hunt and by non-governmental organizations on behalf of opponents of the seal hunt. Icebreaker support was estimated to be $\$ 4.7$ million annually. The federal and Newfoundland governments together allocate a minimum of $\$ 200,000$ annually to lobby in favour of the hunt. Finally, non-governmental organizations (NGOs) allocate substantial resources to oppose the seal hunt. For example, the two largest animal-welfare NGOs that favour an end to the seal hunt each have annual budgets exceeding $\$ 100$ million. Although these budgets are for all their animal-welfare campaigns combined, the seal-hunt campaign is a major priority for both of these organizations. ${ }^{20}$ Therefore, it is not unreasonable to assume that a minimum of $\$ 2$ million is expended annually by all NGOs combined to lobby against the hunt and to be present annually to monitor and observe the hunt. Thus, the estimated aggregate benefit of ending the hunt is a minimum of \$6.9 million annually. In addition are the unknown but substantial savings in the costs of monitoring, enforcement and management currently expended by the federal government.

\section{FIGURE 3 HERE}

These estimates are admittedly imprecise and incomplete. Although they put the aggregate cost of ending the hunt (about $\$ 6.5$ to $\$ 8.7$ million annually) at about the same size as the benefits (about $\$ 6.9$ million annually), recall that conservative assumptions have been made to generate the cost estimates and have significantly underestimated the benefits (because of the lack of data on the federal government's expenditures on managing the hunt but which surely must exceed \$2 million per year). The cost estimate also assumes the market for seal pelts will continue to remain as strong in the future as it has, on average, in the last decade. Recent indications are that this may not be the case, at least in the immediate future. For example, the European Union is considering a bill that would ban the import of all seal products [28]. If passed, this legislation would cause a large reduction in the demand for seal pelts. In addition, recent reports indicate that sealers have largely abandoned the 2009 hunt for grey seals because of a lack of demand for seal pelts [29]. Although this is a very small commercial hunt, it indicates pelt prices are expected to be very low, at least in 2009. In all probability, therefore, the aggregate benefits of ending the commercial hunt outweigh the aggregate costs. ${ }^{21}$

\footnotetext{
${ }^{20}$ The annual report of the International Fund for Animal Welfare [26] shows its annual expenses are \$101.5 million and lists the seals campaign as one of its seven strategic priority areas. The annual report of the Humane Society of the United States [27] lists its total expenses at nearly \$113 million and states that one of its10 goals for 2008 is to "stop the commercial seal hunt in Canada”.

${ }^{21}$ Some have argued that the harp seal population has contributed to the collapse of the Atlantic cod stock and/or inhibited its recovery. McLaren et al [28] review the voluminous literature on this question and concludes that the evidence is mixed. Overall, the authors suggest that over-fishing caused the collapse but predation by seals is most likely contributing to the prevention of cod-stock recovery in some regions but not in others. However, given that the cod
} 
Nevertheless, sensible policy-making would demand a considerably higher level of certainty about this conclusion before implementing a closure of the commercial seal hunt. In the next section, three mechanisms for ending the hunt are examined that are capable of delivering this higher level of certainty.

\section{Mechanisms for Ending the Commercial Hunt}

Sealers must be paid at least their reservation prices ${ }^{22}$ to induce them to voluntarily exit the seal hunting business. If these were public information, government could just buy seal hunters out of the industry at their reservation prices. Provided the total cost is less than the total willingness to pay, the buy-out would then satisfy the Pareto criterion.

In practice, of course, neither the reservation prices nor the total willingness to pay are known with certainty. Nevertheless, all three of the following mechanisms operate as if they were eliciting at least some information about reservation prices and willingness to pay. Programs in which buy-out prices are negotiated between government and sealers at best elicit information about the upper bound for reservation prices but come close to satisfying the Pareto criterion because sealers will only accept a buy-out if it at least meets their reservation price. Reverse auctions, in which sealers submit "bids" for the amount for which they are willing to exit the industry can elicit information about reservation prices and also ensures that sealers are made no worse off. In both cases however, the government can at most represent the willingness to pay of taxpayers; hence the willingness to pay over and above this by opponents to the hunt is not represented. On the other hand, an individual transferable quota system in which the quota market is open to the public, has the potential to elicit information about both reservation prices and willingness to pay and to ensure that the Pareto criterion is satisfied.

Whatever mechanism is used to end Canada's commercial seal hunt, a common challenge will be to determine sealers' eligibility requirements for receiving compensation. At least half of the annually issued seal licenses are inactive and so do not merit compensation. While this is a detail that would ideally be worked out in consultation with the sealing industry, the review of buy-out experiences around the world below suggests that tying the level of compensation to the documented level of activity in recent years is the most commonly used approach.

fishery is already in a collapsed state, it is not likely that an increase in the harp seal population, resulting from an end to the hunt, could have a significant further economic impact in terms of the cod fishery.

${ }^{22}$ In theory, reservation prices of sealers equal the present value of the stream of expected future economic surpluses. Willingness to pay in the case of taxpayers is the present value of the stream of expected savings of government expenditures from ending the commercial hunt. In the case of opponents to the hunt, donations to NGOs to fund opposition to the hunt are at least as high as the willingness to pay to end the hunt. In fact, the free-rider problem means that donations are probably smaller than the total willingness to pay. 


\subsection{Buy-outs and Reverse Auctions}

With a direct buy-out approach, government would attempt to reach a bargaining solution with sealers. To help establish a starting point for a buy-out offer, estimates of sealers' earnings and experience with other buy-out programs could be used. Estimates of sealers' earnings were presented in an earlier section of the paper. Experience with other buy-out programs is discussed below. However, a bargaining solution presupposes that sealers would agree to be uniformly represented by a single bargaining authority on their behalf. If sealers' interests were quite homogeneous, this could happen perhaps but not likely otherwise. And even if a bargaining solution were reached, the government side would still not represent the full willingness to pay to end the hunt.

An alternative is a reverse auction in which eligible sealers submit sealed bids in the amount of money they require to agree to give up sealing forever. Government ranks the bids, from lowest to highest, and accepts all bids up to the point that its budget (the willingness to pay of taxpayers, in principle) is exhausted. Again, the problem is that the total budget does not reflect the total willingness to pay.

\subsection{A Review of Buy-Out Programs}

Buy-out programs and reverse auctions have been used extensively in fisheries around the world. ${ }^{23}$ The programs fall into two categories predominantly; first are those intended to reduce fishing capacity in fisheries that have become overcapitalized and unprofitable; second are those intended to provide financial relief to fishers suffering the effects of a declining or collapsed industry. ${ }^{24}$

The British Columbia salmon fishery has a long history of buy-back programs. On four separate occasions, the federal government has introduced programs designed to reduce fishing capacity. In the 1970-74 program, the 2008 equivalent of nearly $\$ 30$ million was spent by the federal government to buy out licensed fishing vessels. In 1981, another \$5.5 million was spent to buy out more vessels. In 1993, a program to buy back licenses only was introduced and $\$ 8.5$ million was spent to retire about $1.6 \%$ of the industry's harvest capacity. In the 1994-95 period, the most ambitious program of all was introduced. More than $\$ 100$ million was spent by the federal government to reduce the fleet capacity by about $20 \%$.

In the United States Northeast Multispecies groundfish fishery in 1995, a program to provide relief to fishers adversely affected by the collapse of the fishery was introduced. Using a reverse auction, fishers were given the opportunity to submit via sealed bid the amount for which they were willing to sell their license and vessel. Bids were ranked on the basis of the value of the bid divided by the average revenue generated over three of the previous four years. The

${ }^{23}$ This summary is based on Holland et al [31].

${ }^{24}$ The latter type of program of course is not restricted to fisheries. For example, Daniszewski [32] reports that tobacco farmers in the province of Ontario, Canada were recently offered a \$286 million buyout package. 
lowest-ranked bids were successful and were purchased. Up to \$32 million was allocated to the program. Successful bids averaged $49 \%$ to $73 \%$ of their average annual revenues.

In 1977, the Canadian government introduced a program of voluntary license retirements in the Atlantic Inshore lobster fishery. The equivalent of nearly \$17 million was spent compensating those who could document their landing over the previous three years and who were willing to retire their license. Finally, more than $\$ 77$ million was spent buying out fishing licenses and vessels in the Atlantic Canada groundfish fishery following the 1992 moratorium on cod.

The experience with buy-out programs in fisheries discussed above does not provide a great deal of insight into the likely cost of a buy-out of commercial harp sealers. In most cases, the buy-out packages included the purchase of the fishing vessel, not just the fishing rights, making it impossible to disentangle the reservation price for giving up the right to fish from the value of the vessel. A buy-out of the sealing industry would not include purchasing the vessel because the primary role of these vessels is in other fisheries, predominantly the crab fishery.

However, if the experience of the buy-out program in the US Northeast multispecies groundfish fishery is applied, one can obtain an estimate of the buy-out cost of the commercial seal hunt. There, $49 \%$ to $74 \%$ of landed value was the compensation paid. Using $\$ 15$ million as the average landed value in the commercial harp seal industry in the past six years means compensation in the range $\$ 7.35$ million to $\$ 11.1$ million would be the cost of a buyout, amounting to about $\$ 1,050$ to $\$ 1,586$ on average, per eligible seal hunter, assuming 7000 eligible sealers. These amounts are roughly five times the estimated annual earnings per sealer in the weak market of 2008 and slightly lower than annual earnings per sealer in the strong market of 2005. Unfortunately, there is no way of knowing, a priori, whether or not sealers' reservation prices are above or below this range. One of the advantages of the next mechanism discussed is that this information ultimately is revealed by the market.

\subsection{Individual Transferable Quotas}

Individual transferable quota (ITQ) systems were first introduced in the 1970s. Now, hundreds of fisheries are managed under ITQs and over $10 \%$ of global harvest is currently taken under ITQ [33]. Most of the major fishing nations such as Australia, Canada, Chile, Iceland, Namibia, the Netherlands and New Zealand employ ITQs in at least some of their fisheries.

Because an ITQ confers the right to an individual, group, community or enterprise to harvest a pre-determined quantity, it substantially eliminates the "race-to-fish" phenomenon. ${ }^{25}$ Moreover, because individuals have the right to buy and sell ITQs, and because the most efficient fishing units can afford to buy up the quota from the least efficient, a rationalization and reduction in the fishing fleet follows. Consequently, a more evenly-paced and cost-effective

${ }^{25}$ The race to fish is significantly reduced by not eliminated because there remains some pressure to be the first to reach the best fishing areas or, in the case of the seal hunt, the densest whelping patches. However, these pressures are largely alleviated by tying the ITQ to a particular region. 
harvest occurs. For example, the British Columbia halibut fishery which, prior to the introduction of ITQs had a season that lasted six days per year, now has a season lasting 245 days [6].

The empirical evidence reported in Annala [34] and Hatcher [33] suggests that ITQs are, on balance, a good management tool. Fishing effort has usually decreased and fishing fleets have contracted, depleted stocks have recovered and the quality of the landed catch has generally increased. Newell et al [35] and Grafton et al [6] report that ITQs have dramatically improved the economic performance of fisheries. Costello et al [36] argue that ITQs have also improved the sustainability of fisheries. They argue that traditional fisheries management systems such as that now used for harp seals can lead to poor stewardship of the resource and lobbying for everlarger harvest quotas, creating a spiral of reduced stocks, excessive harvests, and eventual collapse. They test the hypothesis that ITQ systems help to prevent the collapse of fisheries using data on over 11,000 fisheries world-wide and find that implementation of ITQs not only stops but reverses the global trend toward widespread collapse.

If an ITQ system were applied to the harp seal hunt, eligibility requirements would again have to be determined and again, and it would be prudent to draw on the considerable experience that now exists with allocating quota in different fisheries around the world Typically, quotas are allocated free of charge though, in principle, they could be sold under auction. Whether the initial allocation should be uniform or related to individual catch histories depends on a number of factors. First and foremost would be the distribution of harvest histories. If the number of pelts taken in recent history is reasonably uniform across licensees, or reasonably uniform within hunting zones, a uniform distribution, or uniform within a zone, of ITQs would be the least-costly method administratively. If harvest histories are highly nonuniform even by zones, however, individual allocations in proportion to average catch or average catch share in the most recent three or four years, though administratively more costly, would be fairer.

Experience shows that ITQ systems work better when the quota stipulates a share of TAC rather an absolute volume of catch. This provides the flexibility for the authorities to adjust the TAC in response to changing biological or economic conditions. For the sake of illustration, suppose that it turns out that 8,000 licensees are eligible to receive an ITQ and suppose, for simplicity, that each would receive an equal allocation. Then, each receives ITQs representing $0.0125 \%$ of the TAC. Suppose the TAC is 272,000 seals. Then an individual quota entitles the owner to harvest about 34 seal pelts. A crew of five, say, on a vessel, that combined their quotas would be entitled to harvest 170 pelts, about the same as the 2005 harvest per vessel.

Theory and empirical evidence suggest that the number of quota holders and number of vessels will decline after the initial allocation as the more efficient buy quota from the less efficient. In addition to rationalizing the industry, this reduces the cost of monitoring and regulating quota holders. For example, Grafton et al [6] report that the number of vessels operating in the British Columbia halibut fishery declined by about $31 \%$ in the three years following the introduction of individual quotas.

Neither of the two main disadvantages associated with ITQs, high-grading and by-catch, would arise in commercial sealing. High-grading and by-catch problems arise because the harvest is not selective so that unintended catch is brought on board. Unintended kills are not likely to arise in seal hunting. 
What are the advantages of adopting an ITQ system for seal hunting? First, the incentive to "race-to-hunt" is reduced. This has important implications not only for the enhanced efficiency of the hunt but for the safety of the hunt. As was discussed earlier, the current management system encourages risk-taking behaviour. This would be significantly reduced under an ITQ system. Not only would this reduce the expected damage to and loss of vessels, it would reduce the demands on the Coast Guard to perform rescue missions. For example, in the Northwest Pacific Halibut fishery, search and rescue missions declined by about $70 \%$ after an ITQ system was introduced [37]. Moreover, Grafton et al [6] report that in a survey of the British Columbia halibut fishery, fishers rated "better safety" as the most important benefit of individual quotas.

Second, an ITQ system establishes the market value of participating in the commercial seal hunt in any given year and in perpetuity. Since the owner of an ITQ has the right to lease it for one season at a time or to sell it permanently, the market for quota would determine an annual lease price and a permanent share price. The market price for a one-season lease would reflect the expected economic surplus from harvesting a share of TAC for one season. The market price for a permanent transfer of a share of TAC would reflect the expected present value of economic surpluses in perpetuity. Thus, if the government chose to end the commercial seal hunt, it could do so by buying up quota. The ITQ system eliminates the uncertainty about the amount of compensation to pay to sealers. Since quota prices will reflect sealers' reservation prices, compensation would be fair and welfare-improving.

Individual share quotas are typically transferable only among licensed fishermen. However, it is proposed here that any individual, group, organization or community be permitted to register to participate in the market for quota, though only licensed seal hunters should be permitted to exercise quota. ${ }^{26}$ Thus, an additional benefit of an ITQ system applied to the commercial seal hunt would be that it provides a market mechanism through which opponents to the seal hunt could express their willingness to pay to reduce and ultimately eliminate the seal hunt. Sealers who hold ITQs would only sell them if they receive at least their reservation price. Opponents to the hunt would only buy ITQs and retire them if the price were no higher than their willingness to pay. Thus, an ITQ and hence a share of TAC, will be retired only when it is a Pareto-improving outcome. If the total willingness to pay exceeds the total of reservation prices, the full amount of TAC would be purchased and retired, the commercial hunt would be effectively ended, and sealers and opponents to the hunt alike would be better off.

For this to work, the government must be able to commit to not increasing the TAC to replace the shares of TAC held and retired by third parties. The most effective way to ensure this happens is to have a transparent process for setting TAC in which there is representation from all quota holders.

Would Canada’s commercial seal hunt likely end if third parties were permitted to

${ }^{26}$ There are precedents for similar third-party purchases. For example, Barringer [38] reports that the Nature Conservancy purchased several trawling licenses and vessels and retired some and modified the gear on others to make them less environmentally destructive off the central California coast. And the Rainforest Conservation Society purchased the license to manage the rights to hunt grizzly bears in 20,000 kilometers of British Columbia rainforest [39]. 
purchase individual quotas? The answer depends on the strength of the willingness to pay to close the hunt and on the elasticity of demand for seal pelts. It is probable that the price of ITQs would be quite low initially, reflecting the fact that the economic surplus is low. Thus, the willingness to pay to buy ITQs should be sufficient to purchase a significant share of the TAC. However, as the number of ITQs and, hence, the annual harvest, declines, the price of seal pelts will rise, all else equal, and this will drive up the price of ITQs. The extent of the price rise will depend on the elasticity of demand for seal fur. This price-effect could very well be the factor that limits the amount of quota that third parties would be able to purchase. It is conceivable that the resulting equilibrium could be a compromise between those opposed to and those in favour of the commercial hunt in which there is more profitable but smaller-scale hunt that is conducted in a more humane and safe way because of the reduced incentive to race-to-hunt. Alternatively, more strategic buying strategies by third parties might emerge. For example, at some point, third parties may offer to purchase the remaining ITQs in a block, conditional on there being no hold-outs. Presumably, a premium over and above market price of ITQs would have to be offered but it is not obvious that there is any guarantee that all sealers would sell. Government appropriation of remaining ITQs may be the only way to guarantee this outcome.

\section{Conclusions}

A strong case can be made for introducing ITQs to Canada's commercial harp seal hunt independently of the argument that it provides a Pareto-improving mechanism for ending the hunt. This is an industry that is criticized for not always complying with regulations governing humane killing methods, regulations that inevitably slow the hunt. And it is an industry in which a culture of risk-taking is pervasive because of the intense competition for a share of TAC. Each of these problems is an unintended consequence of the current resource management regime. Both of these problems would be significantly diminished under an ITQ system. These advantages alone would yield substantial benefits, not just to sealers in the form of increased safety and increased profits, but to taxpayers because of the reduced demands on rescue operations by the Coast Guard, and to society in general because of increased compliance with humane killing regulations.

The evidence suggests that the benefits of ending the commercial harp seal hunt exceed the costs, but not unequivocally. An additional advantage of introducing an ITQ system is that it would help to eliminate the uncertainty about the benefits and costs of ending the hunt. The market for ITQs would establish the size of the expected economic surplus in the commercial seal hunt, and reveal sealers' reservation prices for being bought out of the industry. Buying out all the ITQs is a direct approach by which the Canadian government could end the hunt while at the same time ensuring that sealers are fairly compensated but not over-compensated. If, in addition, third parties, such as animal-welfare NGOs, are permitted to buy ITQs, then a market is created in which those willing to pay to end the hunt can do so directly to the sealers, thereby ensuring a Pareto-improving outcome. 
Figure 1

Harp Seal Catch versus TAC

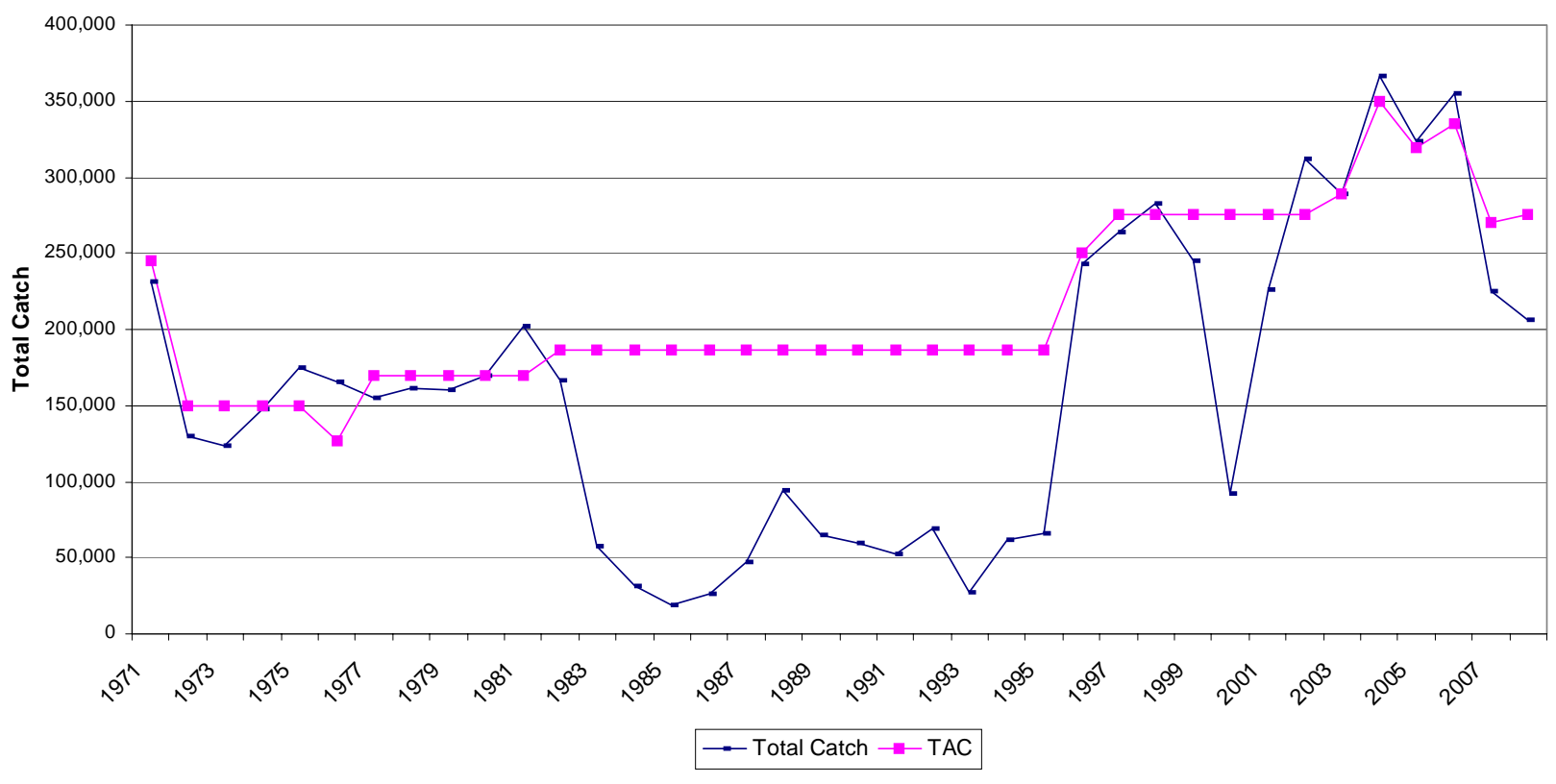

Source: International Council for Exploration of the Sea [4]. 
Figure 2

\section{Landed Value in constant 2008 dollars and Landings} All Regions

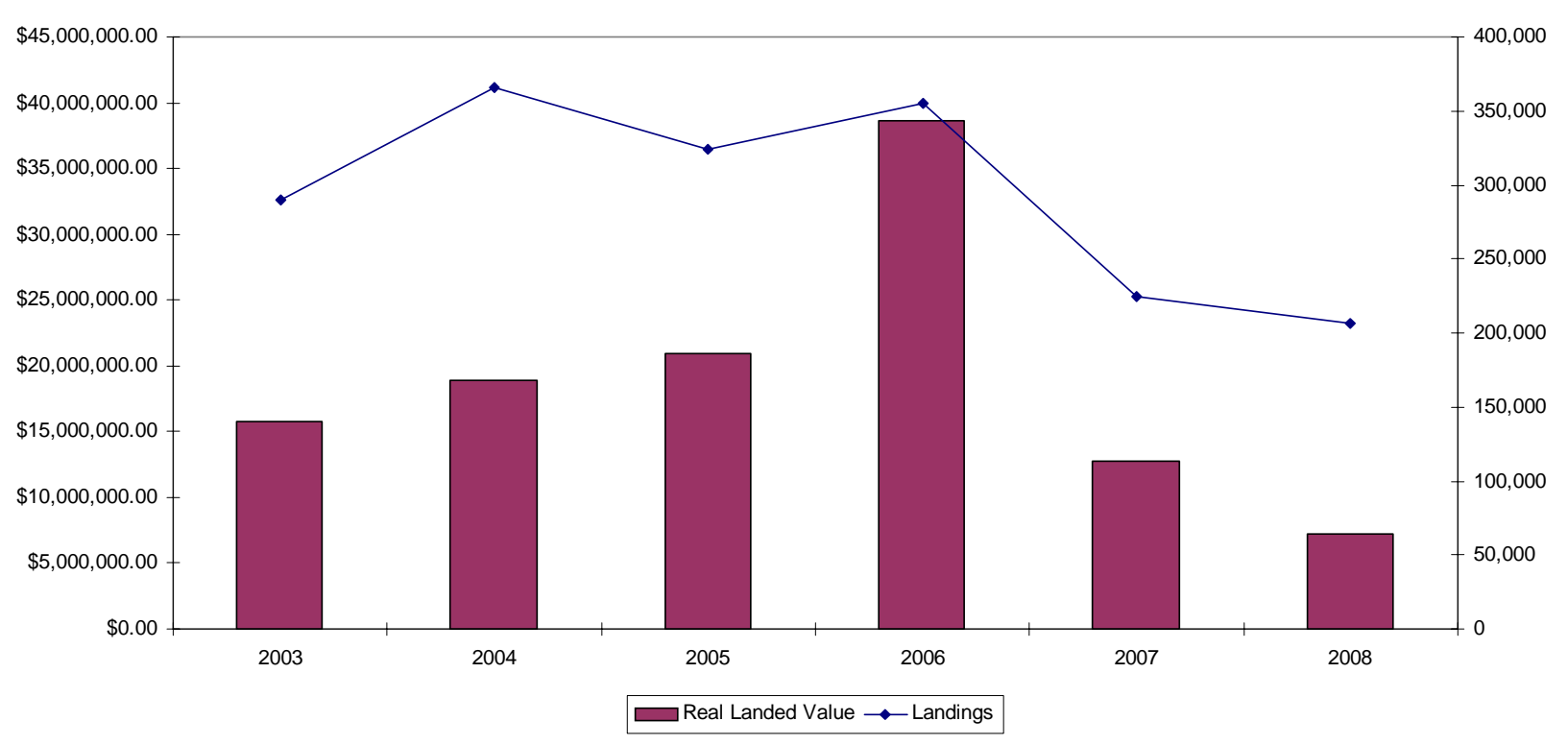

Source: Landings: International Council for Exploration of the Sea [4].

Real Landed Value: DFO [40] provides the total and average nominal landed values for the Newfoundland region only, which comprises about $75 \%$ of the total hunt on average. The estimated real landed value for all regions combined is the average nominal landed value for the Newfoundland region multiplied by the total number of harp seals landed in all regions combined. These values were then adjusted for inflation using the Consumer Price Index. 
Figure 3

Average Seal Pelt Price (constant 2008 dollars)

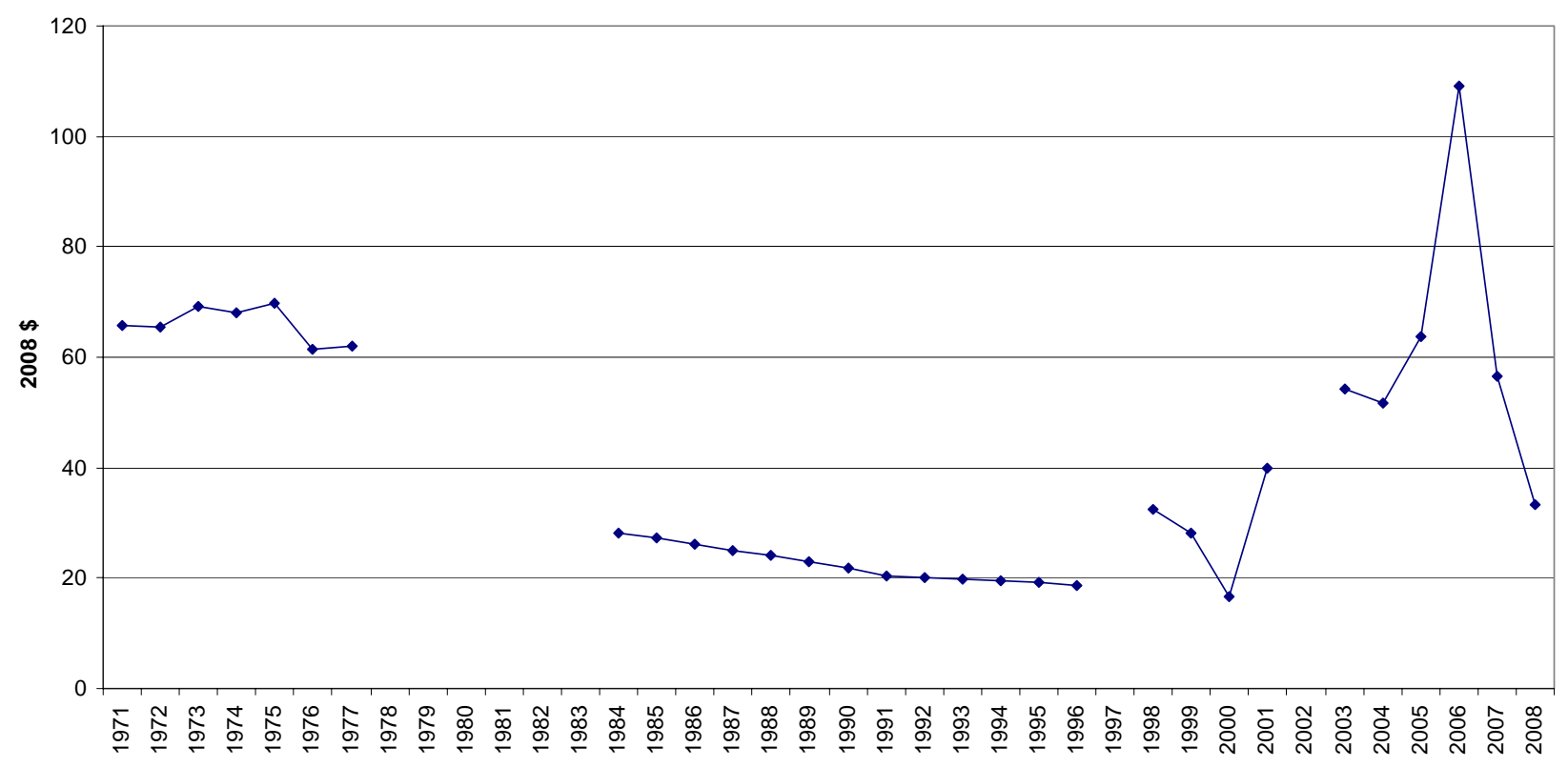

Source: The 2003 to 2008 nominal prices are from DFO [40] statistics on average landed values in the Newfoundland region. The 1998 to 2002 prices are taken from McLaren et al [30]. The mid - 1980s data are taken from the Transportation Safety Board [11] report, which indicates that nominal prices of about $\$ 15$ held throughout the 1980s up to the mid-1990s. Prices from 1971 to 1977 are from Conrad and Bjorndal [41]. All values have been adjusted for inflation to 2008 constant dollars using the CPI. 


\section{Table 1}

\section{Operating Costs per Vessel in the 1996 Hunt (constant 2008 dollars)}

\begin{tabular}{|l|c|c|}
\hline & Small Vessel & Large Vessel \\
\hline Fuel & $\$ 1221.89$ & $\$ 4178.12$ \\
\hline Freight on pelts and meat & $\$ 638.78$ & $\$ 3419.93$ \\
\hline Food & $\$ 360.43$ & $\$ 1500.25$ \\
\hline Ammunition & $\$ 668.27$ & $\$ 2097.12$ \\
\hline Insurance & $\$ 167.07$ & $\$ 2564.95$ \\
\hline Other & $\$ 219.48$ & $\$ 2355.23$ \\
\hline Total Cost per Vessel in 1996 & $\$ 3,275.82$ & $\$ 16,131.73$ \\
\hline
\end{tabular}

Source: Seal Industry Advisory Council [8] and author’s calculations. (See Appendix)

Table 2

Adjusted Operating Cost Estimates for the 2005 Hunt (constant 2008 dollars)

\begin{tabular}{|l|c|c|}
\hline & Small Vessels & Large Vessels \\
\hline Fuel & $\$ 748.50$ & $\$ 2,564.16$ \\
\hline Freight on pelts and meat & $\$ 391.40$ & $\$ 2,096.68$ \\
\hline Food & 0.0 & 0.0 \\
\hline Ammunition & $\$ 151.16$ & $\$ 473.55$ \\
\hline Insurance & $\$ 166.21$ & $\$ 2,566.12$ \\
\hline Other & $\$ 220.48$ & $\$ 2,358.73$ \\
\hline Total Cost per Vessel in 2005 & $\$ 1,677.75$ & $\$ 10,059.25$ \\
\hline
\end{tabular}

Source: Author's calculations. (See Appendix) 


\section{Appendix}

\section{The Operating Cost Model}

DFO [5] reports the number of sealers in 2005 to be 7,000 and the number of vessels to be 1800. Although Transportation Safety Board [11] agrees there were 7000 sealers in 2005 and also in 2008, it puts the number of vessels participating in 2005 at 1470, and gives the breakdown as 1098 small vessels and 372 large vessels. This discrepancy between the two estimates of the number of participating vessels is impossible to reconcile. ${ }^{27}$ Therefore, the following calculations will use the lower number of vessels as this will produce a lower estimate of operating costs.

To estimate $C_{L}$ and $C_{S}$, the operating cost per vessel for large and small vessels, the survey data reported in Seal Industry Advisory Council [8] is used. Table 1 shows the data from the survey, adjusted for inflation to constant 2008 dollars. ${ }^{28}$

No allowance has been made for depreciation in these data. However, given that the sealing season only runs for a few weeks each year, depreciation is not likely to be extensive. The survey includes the cost of supplying food to the sealers. While this is clearly an out-ofpocket cost, it is not an economic cost associated with sealing for our purposes since sealers obviously have food expenses regardless of whether they are sealing or not. Although it is arguable that the food costs are higher than they would otherwise be because food has to be transported to the vessel and calorie intake is undoubtedly higher than normal during sealing activities, none of the food expenses are counted towards the cost of sealing in the interest of erring on the conservative side.

In 1996, a total of 300 vessels participated in the hunt and the average catch was 810 pelts per vessel. In 2005, 1800 vessels participated in the hunt with an average catch of 183 pelts per vessel. Presumably, a vessel operating in1996 spent more time at the hunt, consumed more fuel, spent more on freight and so on, than its counterpart in 2005. It would be inappropriate therefore to assume the 1996 operating cost per vessel applies also to vessels in 2005. To do so would be to assume that all of the operating costs shown in Table 1 are fixed vessel costs that do not vary with the number of pelts harvested. To address this problem, the values in Table 1 are

${ }^{27}$ Discrepancies in seal industry data are not uncommon. McLaren et al [30] report "The Panel has attempted to obtain reliable information on the value of the sealing industry but has found that such data are somewhat imprecise and sometimes lacking in consistency. ... Government should be more transparent with respect to the level of support it provides to the sealing industry, whether directly in the form of subsidies to the industry, or indirectly through research into seals and their management, and the provision of icebreakers during the seal hunt."

${ }^{28}$ The report's data are based on random surveys of vessels of each size. The data presented in the report are values that have been scaled up to the estimated total amounts for the industry based on estimates of the number of vessels of each size that took part in the hunt (200 small 100 large vessels). That scaling is reversed and the resulting values are adjusted for inflation using the CPI to arrive at the values in Table 1. 
adjusted using the methodology outlined in Section 3.3. Doing this produces the values shown in Table 2. The adjusted data show the estimated cost per vessel in each cost category for 2005.

To estimate $C_{T}$, the total operating cost of sealing vessels in 2005, multiply the Total cost per Vessel in Table 2 for small and large vessels by 1098 and 372 respectively, the estimated number of small and large vessels in 2005 and add them together. Doing this gives a total cost for all vessels combined of $\$ 5,584,215$.

The estimated value of $C_{T}$ for 2008 is calculated by repeating the above procedure but using using the harvest per vessel in 2008 of 121 pelts to calculate the adjustment factors. The number of small and large vessels is assumed to be the same as in 2005. Doing this gives a total cost for all vessels combined of \$5, 281,898.

\section{Estimating the Cost of Risk}

The assumption of constant relative risk aversion (CRRA) and a coefficient of risk aversion equal to one implies a logarithmic utility function $U(W)=\ln (W)$ where $W$ represents initial wealth. CRRA implies decreasing absolute risk aversion, a feature consistent with empirical findings that individuals become less averse to bearing a risk of a given loss of wealth, the higher is their level of wealth. If $L$ represents the loss and $\pi$ represents the probability of the loss occurring, then the risk premium, $p$, is implicitly determined by the following expression.

$$
\pi \ln (W-L)+(1-\pi) \ln (W)=\ln (W-\pi L-p)
$$

The left-hand side of the equality is expected utility if the owner bears the risk of the loss. The right-hand side is the certain utility from receiving a certain wealth equal to initial wealth minus the insurance premium $\pi L+p$. The risk premium is the amount that makes the individual indifferent between bearing the risk and being fully insured. The risk premium is calculated separately for each type of loss (lost vessel and damage due to an occurrence), then calculate the insurance premium for each type of loss, and then add the two premiums to get the theoretical willingness-to-pay for insurance. 


\section{References}

[1] Department of Fisheries and Oceans, Canada. Seals and Sealing in Canada. Available at: http://www.dfo-mpo.gc.ca/seal-phoque/index e.htm (accessed February 29, 2009).

[2] Lavigne D.M., Kovacs K.M.. Harps \& Hoods: Ice-breeding seals of the Northwest Atlantic. Waterloo: The University of Waterloo Press; 1988

[3] Industry Canada. HS 430170 - Raw Furskins Whole - Seal. Available at:

http://strategis.ic.gc.ca/sc mrkti/tdst/tdo/tdo.php\#tag. (accessed February 25, 2009).

[4] International Council for Exploration of the Sea. Report of the Working Group on Harp and Hooded Seals. 27 - 30 August 2008. Available at:

http://www.ices.dk/reports/ACOM/2008/WGHARP/directory.asp (accessed February 25, 2009).

[5] Department of Fisheries and Oceans, Canada. Landings and Landed Values by Species. Available at: http://www.nfl.dfo-mpo.gc.ca/publications/reports_rapports/reports_rapports_Eng.htm (accessed February 29, 2009).

[6] Grafton Q R, Squires D, Fox KJ. Private Property and Economic Efficiency: A Study of a Common-Pool Resource. J Law Econ 2000; XLIII: 679 - 713.

[7] Southey C. The Newfoundland Commercial Seal Hunt: An Economic Analysis of Costs and Benefits. 1997. unpublished manuscript.

[8] Seal Industry Advisory Council. Sealing: An Industry in Transition, $2^{\text {nd }}$ Annual Report to Honorable Rear Admiral Fred Mifflin, Minister, Department of Fisheries and Oceans and Honorable John Efford, Minister, Department of Fisheries and Aquaculture..St. John’s Newfoundland; 1996.

[9] European Food Safety Authority. Animal Welfare Aspects of the Killing and Skinning of Seals, Scientific Opinion of the Panel on Animal Health and Welfare. 2007; Available at: http://www.efsa.europa.eu/EFSA/efsa_locale-1178620753812_1178671319178.htm (accessed February 25, 2009).

[10] Daoust P-Y, Crook A, Bollinger TK, Campbell KG, Wong J . Animal welfare and the harp seal hunt in Atlantic Canada, Can Vet J 2002; 43: 687-694.

[11] Transportation Safety Board of Canada. Marine Investigation Report M05L0036, Ice Damage and Subsequent Sinking: Fishing Vessel Justin $M$ off the Magdalen Islands. Quebec. 29 March 2005. 
[12] Transportation Safety Board of Canada. Marine Investigation Report M08M0010, Capsizing While Under Tow: Small Fishing Vessel l'Acadien II $18 \mathrm{~nm}$ Southeast of Cape North, Cape Breton Island. Nova Scotia. 29 March 2008.

[13] Transportation Safety Board of Canada. Marine Investigation Report M97L0021, Sinking of the Fishing Vessel Gilbert D off Îles de la Madeleine. Quebec. 16 March 1997.

[14] Government of Newfoundland and Labrador. News Releases. March 6, 2002. http://www.releases.gov.nl.ca/releases/2002/gsl/0306n07.htm. Available at: (accessed February 25, 2009).

[15] Canada Gazette. Regulations Ammending Marine Mammal Regulations. 2008; Vol. 142 No 52. Available at: http://canadagazette.gc.ca/partI/2008/20081227/html/regle1-e.html (accessed February 29, 2009).

[16] Wiseman M, Burge H., Fishing Vessel Safety Review: Maritime Search and Rescue , Newfoundland Region. Department of Fisheries and Oceans Canada, Coast Guard. 2000. Available at: http://www.safetynet.mun.ca/pdfs/CFVSafetyReview.pdf (accessed February 29, 2009).

[17] Guiso L, Paiella M. The Role of Risk Aversion in Predicting Individual Behaviours, in Chiappori P-A, Gollier C. Competitive Failures in Insurance Markets: Theory and Policy Implications. Cambridge, Ma: The MIT Press, 2006.

[18] Branswell, J, Meaney K. Sealing ship rescue operation costs \$3.4 million. CanWest News Service. 27 July, 2007.

[19] Teitel, M. The millions Ottawa spends subsidizing the seal hunt. National Post. April 17, 2008.

[20] Auditor General of Canada. 1989 Report of the Auditor General of Canada, Chapter 23, Department of Transport-Canadian Coast Guard-Fleet Management, Aids to Navigation and Icebreaking, Office of the Auditor General of Canada. Available at: http://www.oag-bvg.gc.ca/internet/English/parl_oag_198911_e_1161.html (accessed February 27, 2009)

[21] Antle, R. Province outlines anti-protest expenditures. The Telegram (St. John's). Monday, 22 September 2008.

[22] Foreign Affairs and International Trade, Canada. Travel and Hospitality Expenses Reports: International Trade. Loyola Sullivan, Ambassador for Fisheries Conservation Travel Expenses. 2009; Available at:

http://w01.international.gc.ca/dthe-dfva/report-rapport.aspx?lang=eng\&dept=FA\&prof_id $=276 \& y a=2007$ (accessed February 25, 2009) 
[23] White, M. Claim filed against protest ship; Ottawa after costs to maintain seized Farley Mowat. National Post, 29 November 2008.

[24] Feather P, Shaw WD. Estimating the Cost of Leisure Time for Recreation Demand Models, J Environ Econ Manage 1999; 38: 49 - 65.

[25] Amoah-Tuffour J, Martnez-Espineira R. Leisure and the Opportunity Cost of Travel Time in Recreation Demand Analysis: A Re-Examination, MPRA Paper No. 8573. 2008; Available at http://mpra.ub.unimuenchen.de/8573/ (accessed March 4, 2009).

[26] International Fund for Animal Welfare. Annual Report 2007. Available at: http://www.ifaw.org/ifaw_united_states/publications/annual_reports.php (accessed February 29, 2009).

[27] Humane Society of the United States. Annual Report 2007. Available at: http://www.hsus.org/about_us/annual_reports_financial/annual_reports_financial_stateme nts.html (accessed February 29, 2009).

[28] Doucet K. EU Closer to Total Ban on Canadian Seal Products. The Globe and Mail, March 3, 2009.

[29] Meany K. 'Not a Good Time to be Selling Fur': Atlantic Sealers. CanWest News Service. February 10, 2009.

[30] McLaren I, Brault S, Harwood J, Vardy D. Report of the Eminent Panel on Seal Management. Canada: The Department of Fisheries and Oceans; 2001.

[31] Holland D, Gudmundsson E, Gates J. Do Fishing Vessel Buyback programs Work: A Survey of the Evidence, Marine Policy 1999; 23: 47 - 69.

[32] Daniszewski H. Tobacco growers disappointed with buyout. London Free Press Friday August 1, 2008.

[33] Hatcher A, Pascoe S, Banks R, Arnason R. Future Options for UK Fish Quota Management, A Report to the Department for the Environment, Food and Rural Affairs. Portsmouth, UK: Centre for the Economics and Management of Aquatic Resources; 2002.

[34] Annala JH. New Zealand's ITQ System: Have the First Eight Years Been a Success or a Failure, Rev. Fish Biol. Fish 1996; 6:43 - 63.

[35] Newell RG, Sanchirico JN, Kerr S., Fishing Quota Markets. J Environ Econ Manage 2005; 39: 437 - 462.

[36] Costello C, Gaines S. D., Lynham J. Can Catch Shares Prevent Fisheries Collapse? Science 
2008; 321:1678 - 1681.

[37] Economist The. A Rising Tide, Fishing and Conservation.: Vol 388, Issue 8598. Sept. 29, 2008.

[38] Barringer F. Private Efforts to Protect the Coast, The New York Times. November 7, 2007. available at http:/query.nytimes.com/gst/fullpage.html?res=950DE2DB113CF934A35752C1A9619C 8 B63 (accessed March 3, 2009).

[39] Rainforest Conservation Foundation. Guide Outfitter Acquisition. Available at: http://www.raincoast.org/projects/grizzly-bears/guide-outfitter-acquisition/ (accessed March 3, 2009).

[40] Department of Fisheries and Oceans, Canada. Newfoundland Region Statistical Reports, Fish Landings and Landed Values. Available at: http://www.nfl.dfo-mpo.gc.ca/publications/reports_rapports/reports_rapports_3_eng.htm (accessed March 3, 2009).

[41] Conrad J, Bjorndal T. A Bioeconomic Model of the Harp Seal in the Northwest Atlantic, Land Econ 1991; 67: 158 - 71. 